Rowland, L.P., Hoefer, P.F.A., Aranow, H., JR. \& MERRITT, H.H. (1956) Fatalities in myasthenia gravis. Neurology (Minneap.), 6, 307.

SaHAY, B.M., Blendis, L.M. \& GReene, R. (1965) Relation between myasthenia gravis and thyroid disease. Brit. med. J. i, 762.

Simpson, J.A. (1960) Myasthenia gravis: a new hypothesis. Scott. med. J. 5, 419.

SimPSON, J.A. (1964) Immunological disturbances in myasthenia gravis with a report of Hashimoto's disease developing after thymectomy. J. Neurol. Neurosurg. Psychiat. 27, 485.

SimPSON, J.A. (1966) Myasthenia gravis as an autoimmune disease: clinical aspects. Ann. N.Y. Acad. Sci. 135, 506.

Singer, W. \& Sahay, B.M. (1966) Myasthenia gravis, Hashimoto's disease and pernicious anaemia. Brit. med. J. i, 904.

Strauss, A.J.L., Seegal, B.C., Hsu, K.C., BurKholder, P.M., NASTUK, W.L. \& OsSerman, K.E. (1960) Immunofluorescence demonstration of muscle binding complement fixing globulin fraction in myasthenia gravis. Proc. Soc. exp. Biol. (N.Y.), 105, 184 .
Taylor, K.B., Roitt, I.M., Doniach, D., Couchman, K.G. \& Shapland, C. (1962) Autoimmune phenomena in pernicious anaemia: gastric antibodies. Brit. med. J. ii, 1347.

TudHOPE, G.R. \& Wilson, G.M. (1962) Deficiency of vitamin $B_{12}$ in hypothyroidism. Lancet, $\mathbf{i}, 703$.

Van de Velde, R.L., Friedman, N.B., Milch, M. \& SMITH, J. (1966) Muscular elements of the thymus. Fed. Proc. 25, Part 1, 661.

VAN DER GELD, H. \& OOSTERHUIS, H.J.G.H. (1963) Muscle and thymus antibodies in myasthenia gravis. Vox Sang. (Basel), 8, 196.

White, R. G. \& Marshall, A.H.E. (1962) The autoimmune response in myasthenia gravis. Lancet, ii, 120.

Williams, E.D. \& DoniaCH, I. (1962) The postmortem incidence of focal thyroiditis. J. Path. Bact. 83, 255.

Wolf, S.M., Rowland, L.P., Schotland, D.L., MCKinney, A.S., HoEfer, P.F.A. \& ARANOW, H., JR. (1966) Myasthenia as an autoimmune disease: clinical aspects. Ann. N.Y. Acad. Sci. 135, 517.

\title{
Hepatoblastoma presenting as an acute abdomen
}

\author{
M. Nanda Prematilleke \\ M.B.B.S.(Cey.), D.C.P.(Lond.), D.Path.
}

\author{
M. Kumarasinhe \\ F.R.C.S.(Eng.)
}

\author{
C. C. Balasubramaniam \\ D.C.P.(Lond.), M.R.C.P.(Ed.), M.C.Path.
}

General Hospital, Kandy, Ceylon

Primary liver tumours in infants and children are extremely uncommon (Edmondson, 1956). Packard \& Palmer (1955) reported an incidence of only nine cases among 126,000 admissions to a Children's Hospital. Stowens (1959) found only four hepatomas in a series of 2172 tumours in infancy and childhood. Hepatomas are generally evident before the end of the second year of life. Although the sex incidence varies in different series, malignant liver tumours appear to be commoner in male children (Borman, Harbott \& Morris, 1961).

\section{Case report}

The patient, a 6-year-old Sinhalese girl, was admitted to the General Hospital, Kandy (Ceylon) at 23.00 hours on 28 January 1966 with abdominal pain confined to the right iliac fossa of sudden onset that morning. She had vomited twice at the onset. There was no previous history of any significance.

On examination the patient's general condition was good; pulse, $104 / \mathrm{min}$; respiration, $24 / \mathrm{min}$; temperature, $98 \cdot 4^{\circ} \mathrm{F}$. She was tender in both right iliac fossae and the left hypochondrium, but her abdomen was soft. No other abnormality was detected. Urine: no abnormality, WBC $10,000 / \mathrm{mm}^{3}$ (neutrophils $80 \%$, lymphocytes $16 \%$, eosinophils $4 \%$ ).

Next morning her pulse was $98 / \mathrm{min}$, respiration $24 / \mathrm{min}$ and she appeared pale. There was tenderness and guarding in the right iliac fossa. A diagnosis of acute appendicitis was made.

Operation (by M.K.). A right grid-iron incision was made. The peritoneum was blue, and dark brownish blood gushed out on opening the peritoneal cavity. The incision was closed and a long right paramedian incision was made. There was about a pint of free dark blood in the peritoneal cavity. The bleeding was found to occur from a rupture of a tumour of the liver. The tumour was oval in shape $\left(3 \times 2 \times 1 \frac{1}{2}\right.$ in.) and was situated on the inferior surface of the liver about 1 in. to the right of the gall bladder. Greyish friable tumour material and blood was found to exude from a rupture about 1 in. long on its inferior surface. The tumour appeared to be encapsulated. Two slender vascular strands were found to con- 
nect the tumour to the right free margin of the lesser sac. The liver tissue immediately surrounding the tumour was pale in colour but the rest appeared normal and there were no lymph nodes in the hilum. Although the tumour could have been enucleated, it was removed together with a surrounding envelope of liver tissue. The ooze of blood from the liver bed was easily controlled. The wound was closed. The patient was transfused with 2 pints of blood postoperatively. The postoperative course was uneventful.

Pathology. The tumour was a firm ovoid encapsulated mass measuring $3 \times 2 \times 1 \frac{1}{2}$ in. with a rind of pale liver tissue attached to its superior surface. Its cut surface was greyish white in colour and showed several haemorrhagic and necrotic areas (Fig. 1).

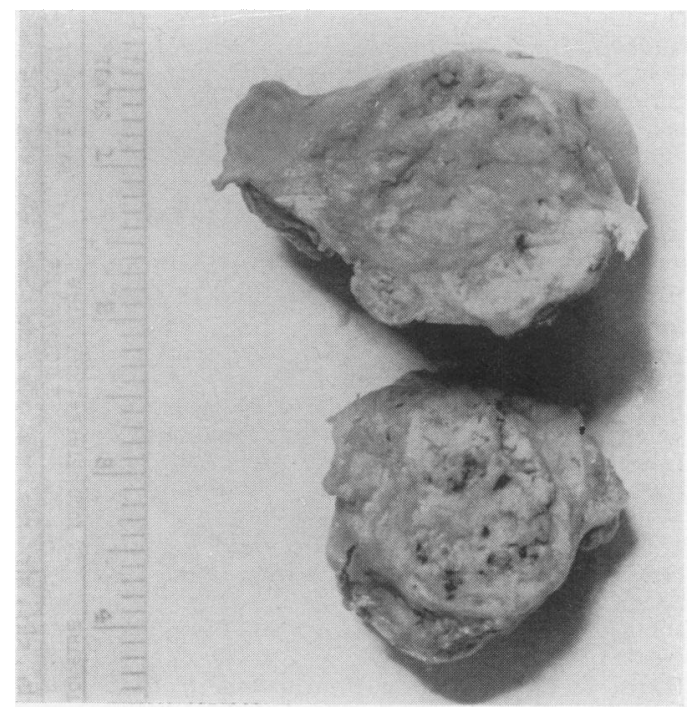

FIG. 1. Cut section of tumour, showing a circumscribed mass with haemorrhagic and necrotic areas.

The tumour tissue was fixed in formol-saline and sections of $5 \mu$ thickness were stained with: (a) haematoxylin and eosin, and (b) by Van Gieson's technique to demonstrate fibrous tissue. Microscopically, the tumour was composed of circumscribed masses of embryonic liver cells separated by fibrous bands. Each of these tumour masses was composed of sheets of darkly staining cells, with little cytoplasm, closely resembling immature liver cells. Giant cells and many mitoses were seen (Fig. 2). In no part of the tumour was normal lobular architecture of the liver seen. The fringe of liver tissue bordering the neoplasm showed moderate fatty change but no evidence of cirrhosis.

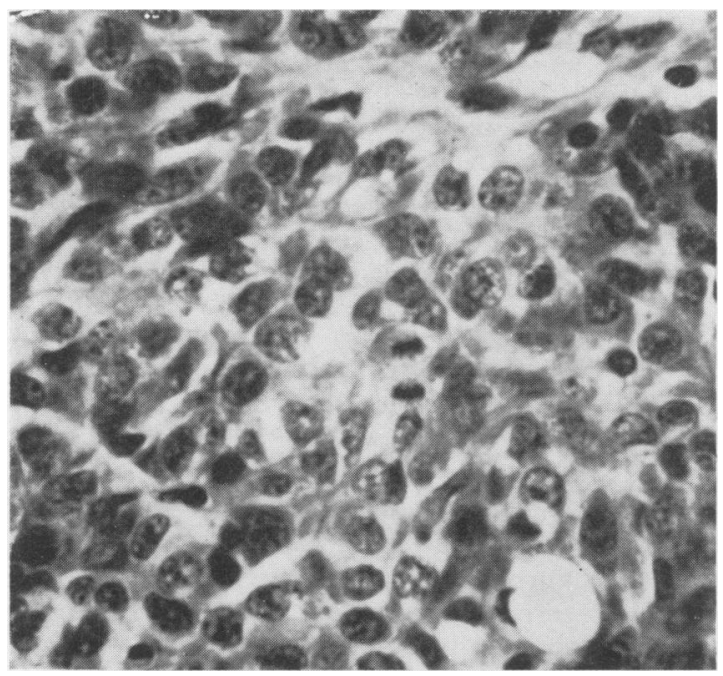

FIG. 2. Section of tumour, showing mitoses and giant cells. Haematoxylin and eosin, $\times 875$.

\section{Discussion}

Hepatoblastomas are embryonic tumours containing hepatic epithelial parenchyma. Webster (quoted by Willis, 1953) has suggested that the embryoma may represent tumour change in a primitive hepatic blastoma analogous to that produced in a renal blastoma by Wilm's tumour. Sometimes this embryonic liver tissue is accompanied by heterotopic elements such as epithelium, osteoid and connective tissue. Accordingly, Willis (1960) subdivides embryonic hepatic tumours into three types: (a) embryonic hepatomas containing only embryonic liver tissue, (b) mixed hepatoblastomas containing bone or cartilage along with hepatic tissue, and (c) rhabdomyoblastic mixed tumours.

The histological appearances of the tumour reported here resembled embryonic liver parenchyma so closely that a diagnosis of hepatoblastoma is justifiable. The absence of bone, cartilage or muscle in the tumour tissue enables us to classify it as an embryonic hepatoma.

Several conflicting statements have been made with regard to the age incidence of hepatoblastomas. Millman \& Grayzel (1951), in a review of twenty-seven cases of mixed embryonal tumours, found that nine cases were adults between 20 and 30 years of age whilst eighteen were children under 8 years. Of the latter, nine were under 1 year, giving an equal incidence in the three age groups, birth to 1 year, 1-8 years and 20-30 years. But most other workers (Willis, 1958 ; Pang, 1961 ; Jolleys, 1965) are of opinion that embryonal liver tumours occur chiefly in infants and children up to the age of 2 years. Willis (1962) 
writing specifically of embryonic hepatomas states that they occur chiefly in young infants and that some of them are known to be congenital. He goes on to say, "The ages when tumours were first noticed in my seven cases were at birth, 4 and 9 months, and 2, 23, 3 and 7 years'. The age of our patient falls in line with Willis' seven cases.

The unusual clinical presentation of the case reported here is also an interesting feature. Edmondson (1956) states that the commonest initial clinical finding in liver tumours of children is the detection of an intra-abdominal mass. Of the seven cases reported by Nixon (1965) four presented with a palpable intra-abdominal tumour as the first sign. In two cases, however, the main complaint was vague malaise whilst in another it was weight loss. Unlike all these cases, the chief clinical manifestations in our patient were rightsided abdominal pain and vomiting with tenderness in the right iliac fossa, simulating acute appendicitis.

Haemoperitoneum due to bleeding from a ruptured tumour in the liver was found at operation in this case. In a review of the literature, Roberts (1961) found that this is a very rare complication of a liver tumour especially in a child. Nissel (quoted by Wells, 1940) was the first to describc such a case in an infant who died shortly after birth and in whom a haemoperitoneum.due to rupture of a large hepatic embryoma was found at autopsy.

In spite of malignant characteristics of the tumour such as hyperchromatism, mitosis, giantcell formation and the embryonal character of tumour cells the absence of metastasis in the abdominal viscera as noted at operation is a favourable finding in this case. Further the encapsulation and the clinically benign nature of the tumour make us speculate whether this case would fall into the type of embryonic hepatoma which is undergoing maturation to form an adenoma as suggested by Willis (1962).

\section{Summary}

Embryonic liver tumours are known to be rare. This is more so in patients above the age of 2 years. A case of embryonic hepatoma in a girl of 6 years is reported. The mode of clinical presentation simulating acute appendicitis and the occurrence of a haemoperitoneum as found at operation are rare features of special interest in this case.

\section{Acknowledgments}

Our thanks are due to Dr R. G. Panabokke of the Department of Pathology, University of Ceylon for helpful discussions and to Mr M. P. A. Jayatilaka for microphotography.

\section{References}

Borman, J.B., Harbott, A.J. \& Morris, D. (1961) Hepatic lobectomy in infancy for hepatoblastoma. Brit. J. Surg. 49, 11.

EDMONDSON, H.A. (1956) Differential diagnosis of tumours and tumour-like lesions of liver in infancy and childhood. Amer. J. Dis. Child. 91, 168.

JoLLEY, A. (1965) Malignant intra-abdominal tumours. Brit. J. clin. Pract. 19, 323.

Millman, D.H. \& Grayzel, D.M. (1951) Mixed tumours of the liver. Amer. J. Dis. Child. 81, 408.

NixON, H.H. (1965) Hepatic tumours in childhood and their treatment by major hepatic resection. Arch. Dis. Childh. 40, 169.

PaCKard, G.B. \& Palmer, H.D. (1955) Primary neoplasms of the liver in infants and children. Ann. Surg. 142, 214.

PANG, S.C. (1961) Bony and cartilaginous hepatoblastoma. J. Path. Bact. 82, 273.

ROBERTS, J.B.M. (1961) Primary hepatic malignancy with particular reference to the embryoma of infancy. Brit. J. Surg. 49, 3.

StOWENS, D. (1959) Paediatric Pathology, p. 498. Williams \& Wilkins, Baltimore.

WELLS, H.G. (1940) Occurrence and significance of congenital malignant neoplasms. Arch. Path. 30, 535 .

Willis, R.A. (1953) Pathology of Tumours. Butterworths, London.

WILLIS, R.A. (1958) The Borderland of Embryology and Pathology. Butterworths, London.

Willis, R.A. (1960) Pathology of Tumours. Butterworths, London.

WILLIS, R.A. (1962) The Pathology of Tumours of Children. Oliver \& Boyd, Edinburgh. 